RESEÑA 

El dulce reato de la Música: La vida musical en Santiago de Chile durante el periodo Colonial The sweet penance of Music: Musical life Colonial Santiago de Chile

Pp. 201 a 203

Alejandro Vera Aguilera

\title{
EL DULCE REATO DE LA MÚSICA: LA VIDA MUSICAL EN SANTIAGO DE CHILE DURANTE EL PERIODO COLONIAL
}

\author{
THE SWEET PENANCE OF MUSIC: MUSICAL LIFE COLONIAL \\ SANTIAGO DE CHILE
}

Oxford University Press (versión inglés) 2020. LCCN 2019052515, 414 pags.

Ediciones Universidad Católica - Fondo Editorial Casa de las Américas

(versión español) 2020.

ISBN 978-956-14-2735-8. 748 pags.

\section{Dr. José Miguel Ramos \\ Universidad de Talca \\ Chile}

Editado en inglés por la prestigiosa editorial de la Universidad de Oxford y en español por la editorial de la Universidad Católica de Chile, este texto obtuvo el Premio de Musicología Casa de las Américas 2018 destacando en su acta de premiación "el uso sobresaliente de fuentes inéditas que, de manera exhaustiva y rigurosa, integran un cuerpo documental de grandes dimensiones, con una estructura clara y fluida". Pero más allá de la riqueza y diversidad de fuentes consultadas, el libro de Alejandro Vera nos invita a escuchar los vestigios de un pasado lejano, expresado en las múltiples voces de una polifonía urbana enriquecida de la interacción étnica y cultural característica del periodo virreinal. A través de una aproximación metodológica novedosa, que si bien toma algunos elementos propios de la musicología urbana, el texto de Vera extiende la mirada más allá del análisis de las estructuras mismas de la sociedad, extrayendo de las fuentes documentales "algo de la voz subjetiva y personal de los sujetos estudiados". Considero este aspecto uno de los más relevantes del libro, ya que sus ricas descripciones nos aproximan a la vida corriente de las personas y no exclusivamente a la relación de éstas 
con las estructuras e instituciones que constriñen su existencia. El resultado, un diálogo ameno y claro, establecido no sólo con otros trabajos enfocados en la historia colonial en general o de la ciudad en particular, sino también con las diversas miradas que las humanidades establecen sobre el periodo. Esta descripción densa, tan vinculada a la disciplina microhistórica, nos devela una vida musical muy alejada de la rigidez con que la historiografía musicológica tradicional construyó el relato musical de Chile, heredado de un nacionalismo decimonónico que constantemente precarizó la cultura colonial en sus más diversas expresiones. El libro de Vera al contrario, revela aspectos novedosos, en que destaca la coexistencia de músicas de diversas épocas y estilos, como reflejo de una sociedad dinámica y heterogénea, enriquecida con la mezcla social de culturas europea, indígena, mestiza y afrodescendiente.

El texto, fruto de una década de investigación en archivos documentales escasamente explorados por trabajos anteriores, nos remite en sus dos primeros capítulos a la vida musical en las instituciones religiosas de la ciudad. En un rigoroso estudio documental enfocado en la actividad musical de la Catedral de Santiago (capítulo 1) el libro no se remite a una historia institucional per se, sino a las constricciones que configuraron el actuar de múltiples personajes, que lejos de los grandes centros virreinales interactuaron constantemente con otras instituciones, latitudes y autoridades. A través del estudio de la capilla catedralicia, en su dimensión económica, organizacional y sonora, el autor entrega interesantes datos relativos a la actividad de maestros de capilla, cantores y ministriles, que vienen a enriquecer nuestro conocimiento de la actividad musical catedralicia en los siglos XVI, XVII y XVIII. Su estudio de la figura de José de Campderros, así como el análisis musical y caligráfico en que destaca su estudio de copistas, nos muestran una institución integrada en el contexto urbano local y virreinal con interesantes vías y ejes de circulación musical hasta ahora desconocidos. La vida musical en los conventos, monasterios y beaterios es tratada de forma notable, (capítulo 2) al reconstruir una vida musical permanentemente interconectada con el entramado urbano.

Aspectos como el ingreso, formación y organización musical en los conventos femeninos por ejemplo, nos muestran a la luz de fuentes inéditas la importancia que revistió para éstos el cultivo de la música, no sólo como actividad ligada a la celebración religiosa, sino también como vehículo de movilidad social. En el caso de los conventos y colegios masculinos, Vera nos entrega interesantes datos relativos a su organización musical e interacción con el mundo extramuros, profundizando en la presencia y características de instrumentos musicales (en que destaca su acucioso estudio de instrumentos de tecla), que junto a la presencia de repertorio y obras tratadísticas, permiten aproximarnos a la real dimensión que la música revistió para estas instituciones. Por otra parte, el texto es sin duda el trabajo más profundo de la vida musical en el ámbito privado del Chile colonial (capítulo 3) resultado de un impresionante trabajo en 
archivos aduaneros y comerciales, que junto al análisis de tratados y discursos configuran una desconocida actividad de importación de instrumentos, libros y objetos musicales a través de una amplia red de ciudades del virreinato del Perú y España. El detallado estudio de la presencia y características de instrumentos musicales, desmitifica el discurso tradicional acerca de la absoluta precariedad y aislamiento que caracterizó a la actividad musical en estos espacios, como también la superación del binomio centro - periferia en la relación de Chile con España y el resto del continente. El espacio público no escapa al retrato de la vida musical de la ciudad (capítulo 4), incluyendo el análisis musical y textual del repertorio que acompaño a fiestas y espectáculos "del nacimiento a la muerte" profundizando en la relevancia que estas funciones cumplieron como medio de representación de la propia sociedad colonial, siendo un rico aporte no sólo para las artes musicales, sino también para el arte dramático y la poesía. Dedicado a las músicas y músicos del Santiago colonial (capítulo 5) el texto se construye franqueando las dificultades que arrastra lo que el autor llama "asimetría entre las fuentes y la realidad estudiada", aspecto que se ve reflejado en las huellas que dejaron quienes se desempeñaron en instituciones y los que no lo hicieron, así como el sexismo propio de la época. A pesar de esto y por medio de ricas descripciones y profundas interpretaciones, Vera deja entrever la expresión misma de quienes fueron los actores de la vida musical santiaguina, en un libro imprescindible en el conocimiento de la cultura y su música en Chile colonial. 